\title{
Feed Temperature Effects on Organic Fouling of Reverse Osmosis Membranes: Competition of Interfacial and Transport Properties
}

\section{Supporting Information}

Sara BinAhmed ${ }^{1}$, Raymond M. Hozalski ${ }^{1}$, Santiago Romero-Vargas Castrillón ${ }^{1,2,3, *}$

Journal: ACS ES\&T Engineering

${ }^{1}$ Department of Civil, Environmental, and Geo- Engineering, University of Minnesota, Minneapolis, MN 55455, USA

${ }^{2}$ Institute for Infrastructure and Environment, School of Engineering, The University of Edinburgh, William Rankine Building, Thomas Bayes Road, Edinburgh EH9 3FG United Kingdom

${ }^{3}$ Institute for Materials and Processes, School of Engineering, The University of Edinburgh, Sanderson Building, Robert Stevenson Road, Edinburgh EH9 3FB United Kingdom

Contents: 17 pages, including 9 figures and 1 table

*Corresponding author:

Santiago@ed.ac.uk,sromerov@umn.edu. Tel: +44(0)1316513567 


\section{Supporting Materials and Methods}

\section{S.1. Reverse osmosis setup, membrane transport properties and fouling experiments}

Reverse osmosis setup. We conducted fouling experiments in a laboratory-scale membrane filtration system comprising a crossflow cell (CF042D, Sterlitech, Kent, WA) with 42-cm ${ }^{2}$ active membrane area and a 20 -L stainless steel feed tank. The feed temperature was set by a portable chiller (6500 series, Polyscience) equipped with a heat exchange coil immersed in the feed tank. A high-pressure pump (HydraCell M-03S, Wanner Engineering, Minneapolis, MN) circulated the feed solution. The permeate flowrate was recorded with a digital flow meter (SLI-2000, Sensirion, Stäfa, Switzerland) and logged to a computer every $0.2 \mathrm{~s}$. The system was operated in closed-loop mode, recycling the permeate and retentate streams to the feed tank.

Determination of membrane permeance to water. Membranes were compacted with an ultrapure (UP) water (18.2 M $\Omega \mathrm{cm}$, Barnstead) feed at 500-580 psi and $25^{\circ} \mathrm{C}$ until a steady-state permeate flux was observed (typically within $\sim 60$ hours). Next, the transmembrane pressure difference was adjusted so that the permeate flux was $20 \pm 1 \mathrm{~L} \mathrm{~m}^{-2} \mathrm{~h}^{-1}(\mathrm{LMH})$, typical of wastewater reclamation by $\mathrm{RO},{ }^{1,2}$ at $15.8 \mathrm{~cm} \mathrm{~s}^{-1}$ crossflow velocity. At this stage, the water permeance at $25^{\circ} \mathrm{C}\left(A_{\mathrm{w}, 25}\right)$ was calculated. Next, the chiller settings were adjusted to maintain the feed at the desired temperature, $T=27,35$, or $40{ }^{\circ} \mathrm{C}$, and the pressure difference $\left(\Delta p_{\mathrm{w}, \mathrm{T}}\right)$ was reduced to maintain a pure water flux of $J_{\mathrm{w}, \mathrm{T}}=20 \pm 1 \mathrm{LMH}$ at the corresponding temperature $T$. The system was run overnight to reach steady-state operation at $T$, after which the water permeance at $T\left(A_{\mathrm{w}, \mathrm{T}}\right)$ was calculated using $A_{\mathrm{w}, \mathrm{T}}=J_{\mathrm{w}, \mathrm{T}} / \Delta p_{\mathrm{w}, \mathrm{T}}$.

Fouling experiments. To begin the fouling experiment, the pure water feed was replaced with foulant-free synthetic wastewater (SWW) with the following composition: $0.45 \mathrm{mM} \mathrm{KH}_{2} \mathrm{PO}_{4}$, $0.935 \mathrm{mM} \mathrm{NH}_{4} \mathrm{Cl}, 0.5 \mathrm{mM} \mathrm{CaCl}_{2}, 0.5 \mathrm{mM} \mathrm{NaHCO}_{3}, 9.20 \mathrm{mM} \mathrm{NaCl}$, and $0.61 \mathrm{mM} \mathrm{MgSO}_{4}{ }^{3,4}$ This synthetic wastewater recipe is representative of secondary effluent in certain wastewater treatment plants in California. The system was again allowed to reach steady state at feed temperature $T=27,35$, or $40{ }^{\circ} \mathrm{C}$ and a baseline permeate flux $J=20 \pm 1 \mathrm{LMH}$. The conductivity of feed and permeate was measured using a conductivity meter with automatic temperature compensation (WD-35604-00, Con 6+ Meter, Oakton) to determine the conductivity rejection coefficient. ${ }^{4}$ Finally, the synthetic wastewater feed was supplemented with sodium alginate (SA) foulant solution to initiate the accelerated fouling experiment at an alginate feed concentration of $250 \mathrm{mg} \mathrm{L}^{-1}$ while recording the permetate flow for 24 hours. Feed and permeate samples were collected 2 and 24 hours after the addition of alginate to determine conductivity and total organic carbon (TOC) rejection. TOC was measured using a Sievers 900 portable TOC analyzer (GE Analytical Instruments, Boulder, CO) that uses the 5310C National Environmental Methods Index (NEMI) standard method. ${ }^{5}$ The feed was diluted $20 \times$ before analysis while the permeate was analyzed without dilution.

Fouling of Reverse Osmosis Membranes for Colloidal-Probe AFM. To perform adhesion force measurements over a fouled membrane, an alginate layer was deposited on a pristine membrane using a dead-end filtration cell (Amicon stirred cell 8010, Millipore). To this end, $3 \mathrm{~mL}$ of synthetic wastewater (SWW) prepared as described above, supplemented with $50 \mathrm{mg} \mathrm{L}^{-1}$ sodium alginate, was filtered through the membrane at 60 psi for 45 minutes. 


\section{S.2. Characterization of membrane interfacial properties}

Contact angle: The wettability of pristine ESPA2-LD membranes as a function of temperature was evaluated in terms of water contact angle measurements using the sessile drop method. Desiccatordried membrane coupons were attached to a glass slide using two-sided tape (Scotch $\mathbb{R}, 3 \mathrm{M})$. A goniometer (DSA30S, Krüss) equipped with a temperature-controlled chamber (TC30) and temperature-controlled liquid dispenser (TC 3212) was used to measure the contact angle of 2- $\mu \mathrm{L}$ water droplets deposited on the membrane substrate. Right-hand-side and left-hand-side angles were determined from digital images using the proprietary ADVANCE software of the instrument for a total of 20 contact angle measurements at each temperature. Measurements were collected at least 15 minutes after both the chamber and UP water reached the set-point temperature $(T=27$, 35 , and $40{ }^{\circ} \mathrm{C}$ ). Contact angles were immediately recorded after the $2-\mu \mathrm{L}$ water drop was deposited.

Roughness: The nanoscale surface roughness of pristine membranes was measured by tapping mode AFM in aqueous solution using an atomic force microscope (MFP-3D-Bio, Asylum Research) equipped with a temperature-controlled fluid cell. AFM scanning was performed in foulant-free synthetic wastewater $(I=14.7 \mathrm{mM}$, see section S.1 or 2.2$)$ at 27,35 , and $40^{\circ} \mathrm{C}$ using SNL-10 probes (cantilever " $\mathrm{C}$ ", nominal $k=0.24 \mathrm{~N} / \mathrm{m}, f=56 \mathrm{kHz}$, Bruker). The temperature of the fluid cell was increased from ambient to the target temperature $T=27,35$, or $40{ }^{\circ} \mathrm{C}\left( \pm 0.2{ }^{\circ} \mathrm{C}\right)$ at a rate of $1{ }^{\circ} \mathrm{C} / \mathrm{min}$. After allowing the AFM to equilibrate at the target temperature for at least an hour, the cantilever resonance frequency was calibrated. Three $5 \times 5-\mu \mathrm{m}^{2}$ scans were collected at each temperature at a $0.25 \mathrm{~Hz}$ scan rate, after which the root-mean-square (RMS) roughness $\left(R_{\mathrm{RMS}}\right)$ of 5 random $1 \times 1-\mu \mathrm{m}^{2}$ subareas on each image were computed for a total of $15 R_{\mathrm{RMS}}$ values.

Surface charge: An electrokinetic analyzer (SurPASS, Anton Paar) was used to measure the streaming potential of ESPA2 membranes in a $1 \mathrm{mM} \mathrm{KCl}$ background electrolyte solution. Two $10 \times 20-\mathrm{mm}^{2}$ membrane coupons were attached to sample holders of an adjustable gap cell. The electrolyte solution was maintained at a constant temperature (monitored using a thermocouple connected to the electrokinetic analyzer) by placing the solution on a heating stir plate. The zeta potential was calculated from the streaming potential using the Smoluchowski-Helmholtz equation. Prior to the measurements, an instrument validation run was carried out using a cotton cloth $\left(\sim 4 \times 4 \mathrm{~cm}^{2}\right)$ following a protocol provided by the manufacturer. Streaming potential data were collected over the $\mathrm{pH}$ range $4-10$ by addition of aliquots of $0.05 \mathrm{mM} \mathrm{NaOH}$ or $\mathrm{HCl}$. Duplicates at each temperature were analyzed. Additional details of zeta potential measurements can be found in our previous work..$^{6-8}$ 


\section{S.3. Calculation of permeate drag force}

The approach loading force (also known as trigger force, Figure S3) exerted on the colloidal probe during AFM force measurements was set to a value representative of the drag force $\left(F_{\mathrm{D}}\right)$ exerted on a colloidal particle during membrane filtration. The permeate drag force $\left(F_{\mathrm{D}}\right)$ was calculated following the analysis by Goren ${ }^{9}$, where the resistance to the approach of a sphere is affected by the permeability of the membrane (considered as a permeable wall).

Goren's analysis ${ }^{9}$ leads to the following expression for the permeate drag force,

$$
F_{\mathrm{D}}=-6 \pi \mu a_{\mathrm{p}} J \Phi_{\mathrm{H}}
$$

where $F_{\mathrm{D}}$ is the permeate drag force $(\mathrm{N})$, and the negative sign indicates that the force is normal to and directed toward the surface of the membrane ${ }^{10} ; \mu$ is the dynamic viscosity of water $\left(\mathrm{kg} \mathrm{m}^{-1} \mathrm{~s}^{-}\right.$ $\left.{ }^{1}\right) ; a_{\mathrm{p}}$ is the colloidal probe radius $(\mathrm{m}) ; J$ is the permeate water flux $\left(\mathrm{m} \mathrm{s}^{-1}\right)$; and $\Phi_{\mathrm{H}}$ is a hydrodynamic correction factor to Stokes drag force., ${ }^{9,10}$

The hydrodynamic resistance to the particle motion toward the membrane decreases with increasing permeability. When the particle is in contact with the permeable wall, the hydrodynamic correction factor is given by Goren ${ }^{9}$ as,

$$
\Phi_{\mathrm{H}}=\left(\frac{2 R_{\mathrm{m}} a_{\mathrm{p}}}{3}\right)^{\frac{1}{2}}
$$

where $R_{\mathrm{m}}=\frac{\Delta p}{\mu J}$ is the membrane hydraulic resistance $\left(\mathrm{m}^{-1}\right)$, and $\Delta p$ is the transmembrane pressure difference $(\mathrm{Pa})$,

The value of $R_{\mathrm{m}}$ of ESPA2-LD RO membranes was determined experimentally in a laboratoryscale crossflow RO setup operating at a pure water flux $J=20 \pm 1 \mathrm{LMH}$ and $25{ }^{\circ} \mathrm{C}$. Three membrane specimens were thus characterized. Flux and corresponding transmembrane pressure values are shown in Table S1. $R_{\mathrm{m}}$ was calculated for each membrane specimen; the resulting values were within the range of typical RO resistance values $\left(5 \times 10^{13}-1 \times 10^{15} \mathrm{~m}^{-1}\right) \cdot{ }^{11}$ Using $a_{\mathrm{p}}=$ $2 \mu \mathrm{m}$ (the radius of the CML particle), $\Phi_{\mathrm{H}}$ was calculated using equation S.2 and used to find the drag force from S.1. 
Table S1: Experimentally determined pure water flux $\left(J_{\mathrm{w}}\right)$, calculated membrane resistance $\left(R_{\mathrm{m}}\right)$ and permeate drag force $\left(F_{\mathrm{D}}\right)$.

\begin{tabular}{|c|c|c|c|c|}
\hline$\Delta p($ bar $)$ & $\boldsymbol{J}_{\mathbf{w}}(\mathbf{L M H})$ & $\boldsymbol{R}_{\mathbf{m}}\left(\mathbf{m}^{-\mathbf{1}}\right)$ & $\begin{array}{c}\text { Hydrodynamic } \\
\text { Correction } \\
\text { Factor } \Phi_{\mathrm{H}}\end{array}$ & $\boldsymbol{F}_{\mathbf{D}}(\mathbf{n N})$ \\
\hline 4.34 & 20.1 & $8.73 \times 10^{13}$ & $1.08 \times 10^{4}$ & 2.02 \\
\hline 4.83 & 20.0 & $9.77 \times 10^{13}$ & $1.14 \times 10^{4}$ & 2.13 \\
\hline 4.27 & 19.6 & $8.81 \times 10^{13}$ & $1.08 \times 10^{4}$ & 1.98 \\
\hline \multicolumn{5}{|c|}{ Average } \\
\hline
\end{tabular}




\section{S.4. Estimation of the foulant layer thickness and mass of adsorbed alginate}

We computed an order-of-magnitude estimate of the mass of alginate adsorbed on the polyamide layer as follows.

The hydraulic resistance due to the foulant $\left(R_{f}\right)$ calculated from our experimental data at $27^{\circ} \mathrm{C}$, under which the most severe fouling is observed, is $0.14 \mathrm{bar} \mathrm{L}^{-1} \mathrm{~m}^{2} \mathrm{~h}\left(140 \mathrm{bar} \mathrm{m}^{-1} \mathrm{~h}\right)$. This is related to the permeability $\left(P_{f}\right)$ and thickness $\left(l_{f}\right)$ of the alginate film through ${ }^{12}$

$$
R_{f}=\frac{l_{f}}{P_{f}}
$$

Olivas et al. ${ }^{13}$ reported values of $P_{f} \sim O\left(10^{-9}\right) \mathrm{g} \mathrm{m}^{-1} \mathrm{~s}^{-1} \mathrm{~Pa}^{-1}=O\left(10^{-7}\right) \mathrm{m}^{2} \mathrm{~h}^{-1} \mathrm{bar}^{-1}$ for the permeability of water vapor in alginate films. Using this value to solve for $l_{f}$ we obtain,

$l_{f}=\left(140 \mathrm{bar} \mathrm{m}^{-1} \mathrm{~h}\right)\left(10^{-7} \mathrm{~m}^{2} \mathrm{~h}^{-1} \mathrm{bar}^{-1}\right) \sim O\left(10^{-5}\right) \mathrm{m}=10 \mu \mathrm{m}$

This estimate agrees with the thickness of alginate foulant layers $(O(10) \mu \mathrm{m})$ following RO filtration reported by Xie et al. ${ }^{14}$

Finally, we can estimate the mass of adsorbed alginate $\left(m_{f}\right)$ using the value reported by Kube et al. ${ }^{15}$ for the density of alginate $\left(\rho_{f}=0.8755 \mathrm{~g} \mathrm{~cm}^{-3}\right)$,

$m_{f}=\rho_{f} l_{f} A_{f} \approx\left(0.8755 \mathrm{~g} \mathrm{~cm}^{-3}\right)\left(10^{-3} \mathrm{~cm}\right)\left(42 \mathrm{~cm}^{2}\right)=0.037 \mathrm{~g}=37 \mathrm{mg}$

, where $A_{f}$ was assumed to be equal to the projected surface area of the membrane (i.e., we assumed complete coverage of the membrane coupon by alginate). Xie et al. ${ }^{14}$ reported a surface density of alginate foulant layers on RO membranes of $\approx 0.7 \mathrm{mg} \mathrm{cm}^{-2}$; using the same surface area as in our system, this yields an adsorbed mass of alginate of $\approx 30 \mathrm{mg}$, in good agreement with our estimate based on $l_{f}$ and $\rho_{f}$.

These calculations show that the mass of adsorbed alginate is ca. 3\% of the mass of alginate available in the bulk solution (i.e., $0.25 \mathrm{~g} \mathrm{~L}^{-1} \times 4 \mathrm{~L}=1 \mathrm{~g}$ ). We therefore conclude that the slowdown of the rate of fouling is not due to a lower concentration of foulant in the feed. Rather, the decreasing rate of flux loss results from weakly adhesive or repulsive foulant-foulant interactions (Figure 3). 


\section{Supporting Results}

a)

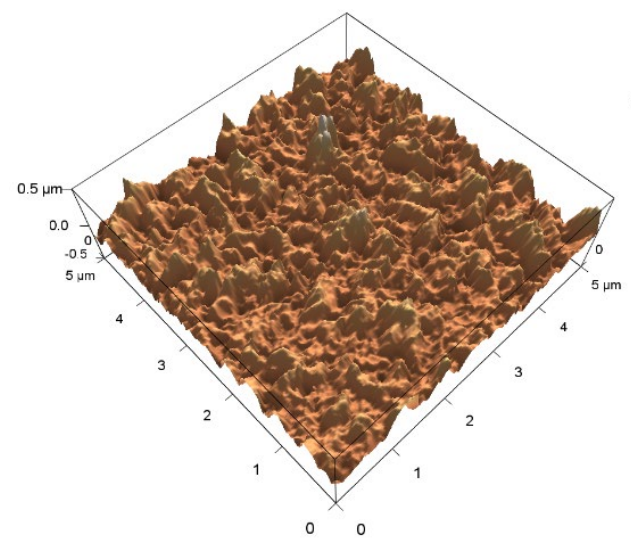

b)

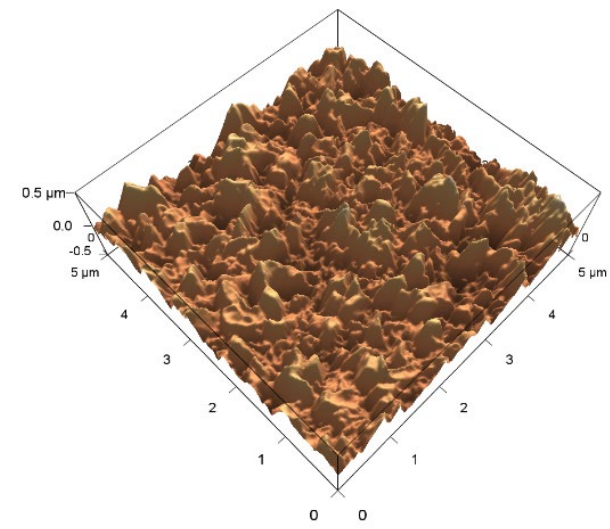

c)

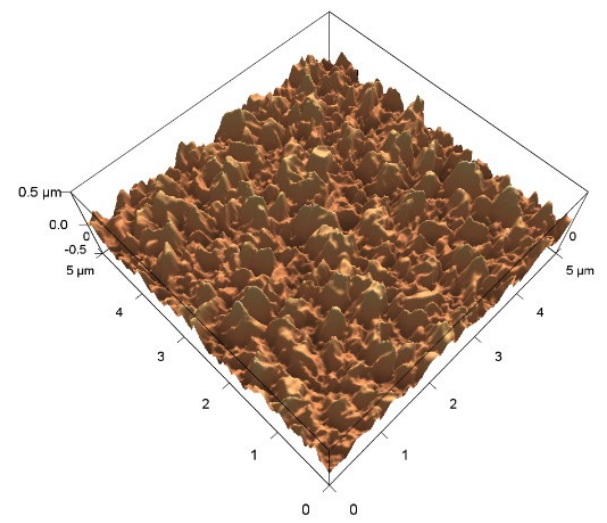

d)
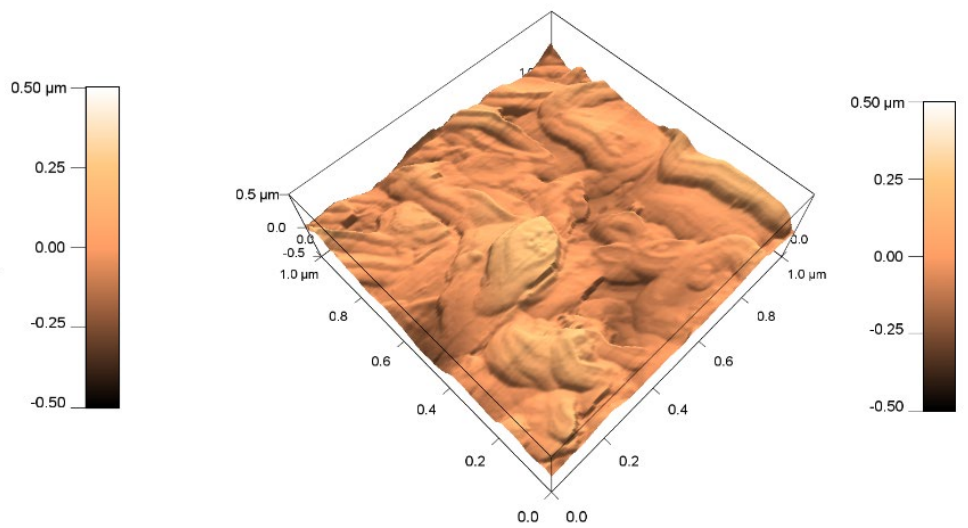

e)
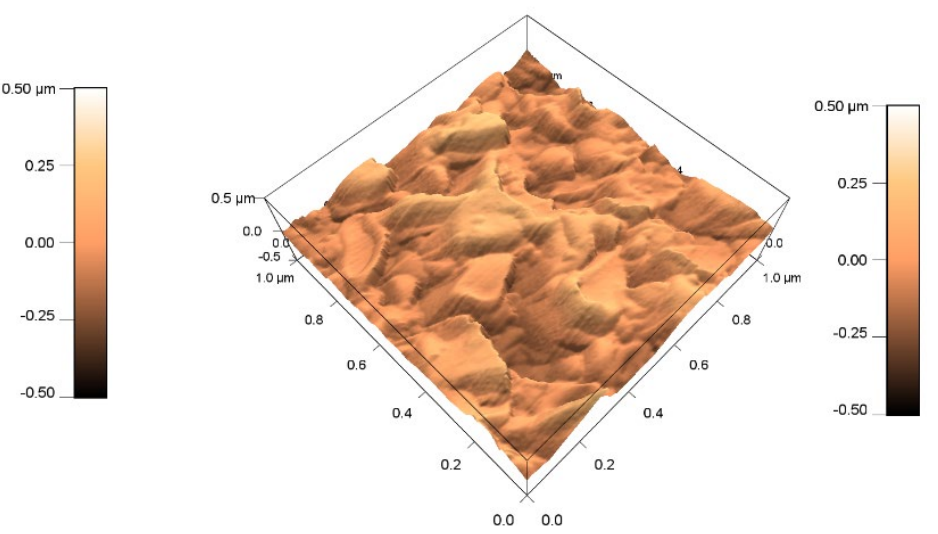

f)

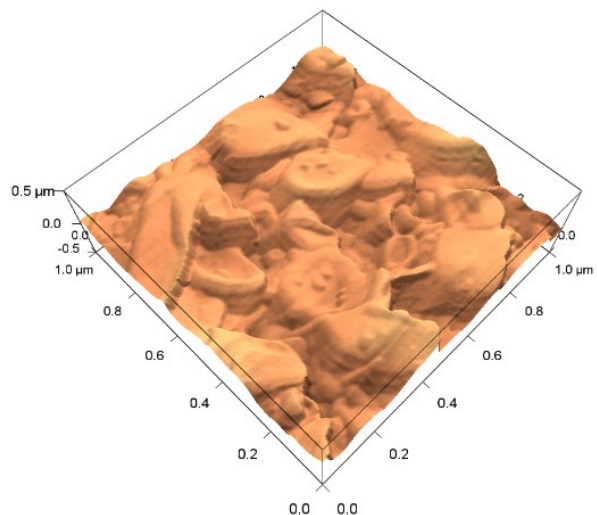

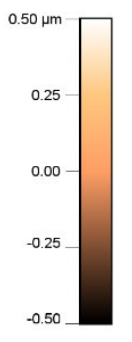

Figure S1: Tapping mode AFM images of pristine ESPA2-LD membranes scanned in foulant-free synthetic wastewater $(\mathrm{pH} 7.4 ; I=14.7 \mathrm{mM})$ at $27{ }^{\circ} \mathrm{C}(\mathrm{a}, \mathrm{d}), 35^{\circ} \mathrm{C}(\mathrm{b}, \mathrm{e})$, and $40{ }^{\circ} \mathrm{C}(\mathrm{c}, \mathrm{f})$. Left column: $5 \times$ $5 \mu \mathrm{m}^{2}$ scan area. Right column: $1 \times 1 \mu \mathrm{m}^{2}$ scan area. 


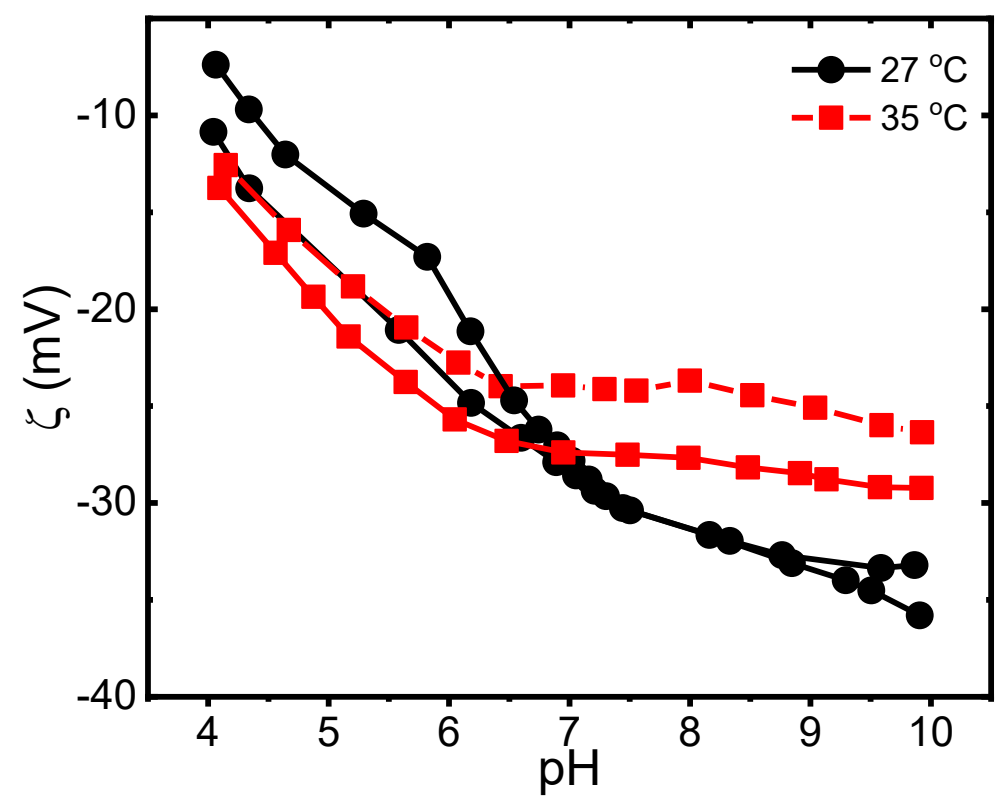

Figure S2: Zeta potential $(\zeta)$ of pristine ESPA2-LD membranes at $27{ }^{\circ} \mathrm{C}$ and $35^{\circ} \mathrm{C}$ determined in $1 \mathrm{mM}$ $\mathrm{KCl}$ solution. Duplicates are shown at each temperature. 


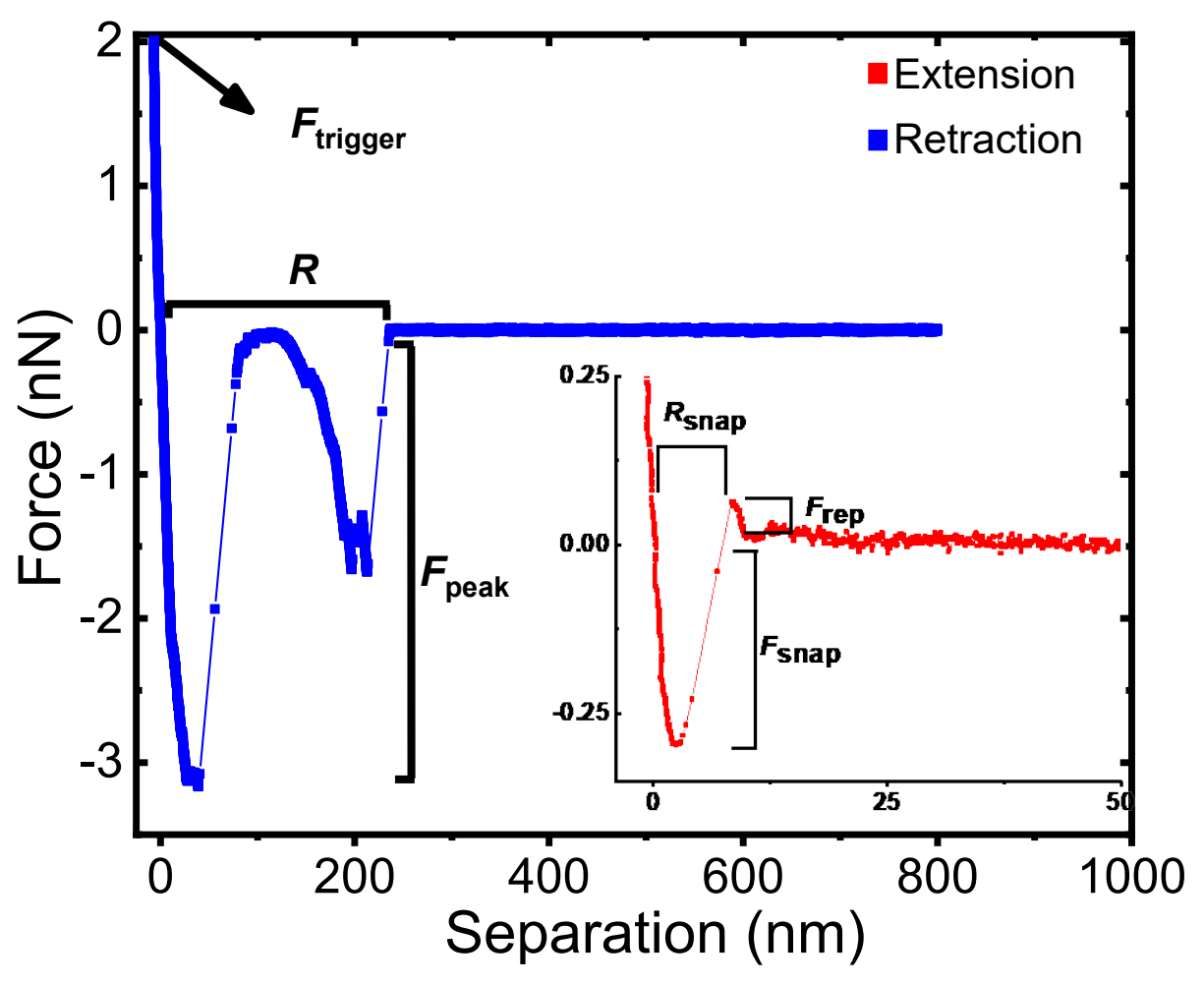

Figure S3: Representative retraction force curve and approach force curve (shown in the inset) of a CML colloidal probe on a pristine ESPA2-LD membrane at $27^{\circ} \mathrm{C}$. Data were collected in synthetic wastewater supplemented with $20 \mathrm{mg} \mathrm{L}^{-1}$ sodium alginate $\left(t_{\text {contact }}=5 \mathrm{~s} ; F_{\text {trigger }}=2 \mathrm{nN} ; \mathrm{pH} 7.4 ; I=14.7 \mathrm{mM}\right)$. The curve shows the definition of the peak adhesion force $\left(F_{\text {peak }}\right)$, snap-in force $\left(F_{\text {snap }}\right)$, trigger force $\left(F_{\text {trigger }}\right)$, rupture separation $(R)$, snap-in separation $\left(R_{\text {snap }}\right)$, and repulsive force $\left(F_{\text {rep }}\right)$. The units of the $x$ - and $y$-axes in the inset are $\mathrm{nm}$ and $\mathrm{nN}$, respectively. 

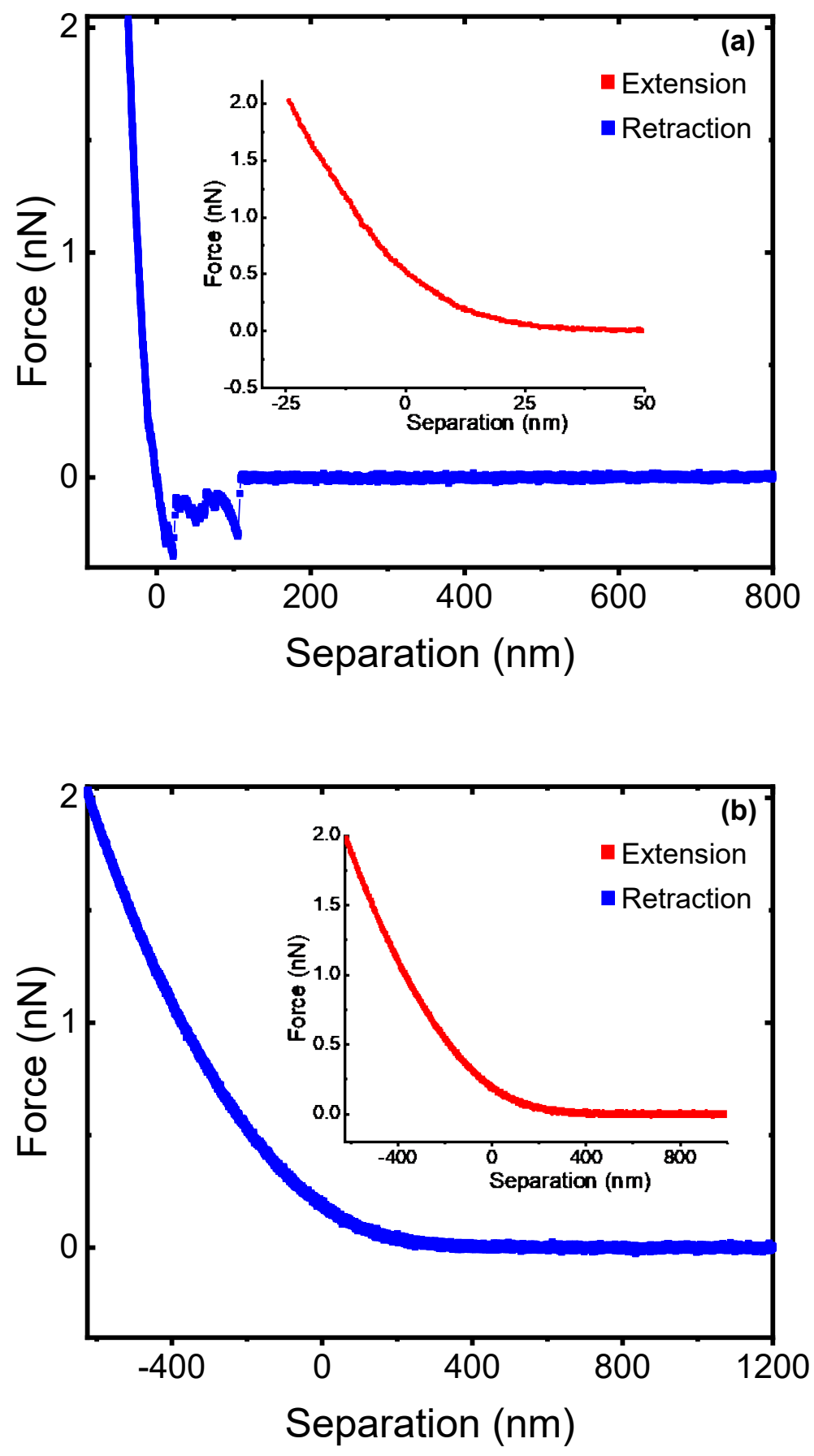

Figure S4: Representative retraction and approach force curves (the latter shown in the inset) of a CML colloidal probe on an alginate-fouled ESPA2-LD membrane at $27^{\circ} \mathrm{C}$. Panel (a) shows a typical force curve exhibiting repulsive interactions during extension, and weak adhesion during retraction. Panel (b) shows the case of repulsive interactions during extension and retraction. Data were collected in synthetic wastewater supplemented with $20 \mathrm{mg} \mathrm{L}^{-1}$ sodium alginate $\left(t_{\text {contact }}=5 \mathrm{~s} ; F_{\text {trigger }}=2 \mathrm{nN} ; \mathrm{pH} 7.4 ; I=14.7 \mathrm{mM}\right)$. 

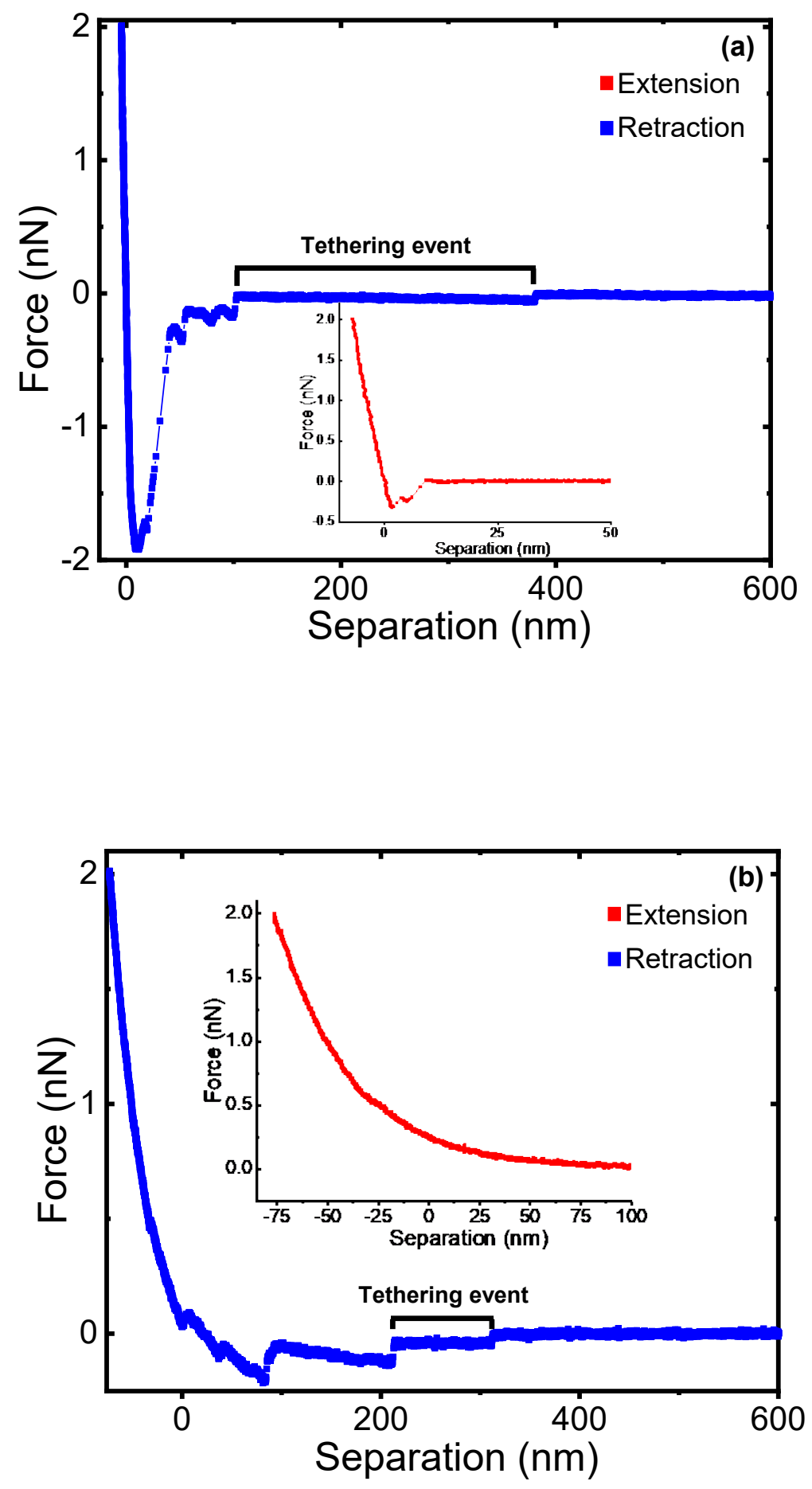

Figure S5: Representative retraction force curve exhibiting a tethering event during adhesion of a CML colloidal probe at $27^{\circ} \mathrm{C}$ on an ESPA2-LD (a) pristine and (b) alginate-fouled membrane (approach force curves shown in the inset). Data were collected in synthetic wastewater supplemented with $20 \mathrm{mg} \mathrm{L}^{-1}$ sodium alginate $\left(t_{\text {contact }}=5 \mathrm{~s} ; F_{\text {trigger }}=2 \mathrm{nN} ; \mathrm{pH} 7.4 ; I=14.7 \mathrm{mM}\right)$. 

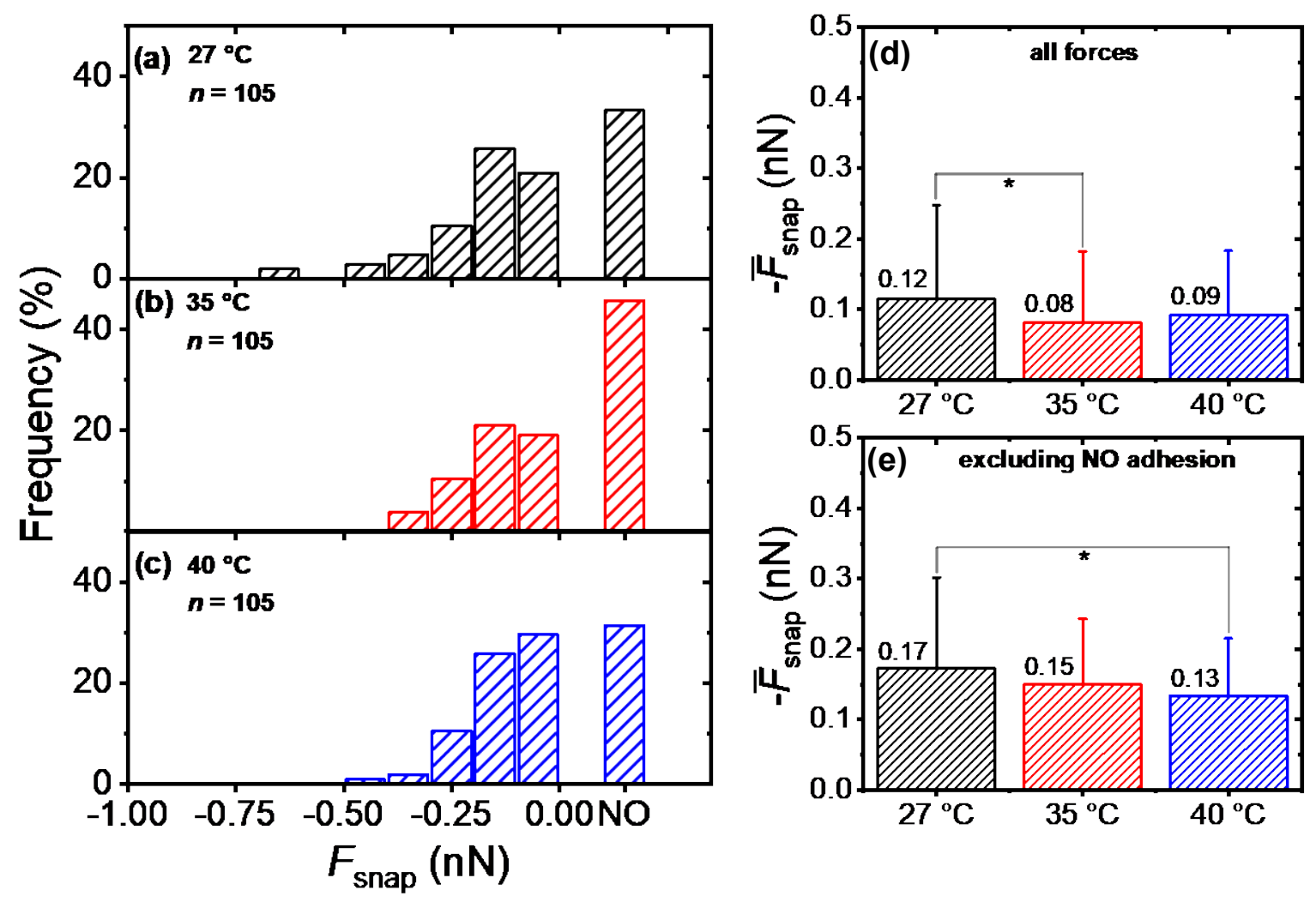

Figure S6: (a-c) Distribution of snap-in forces during adhesion of a CML colloidal probe to pristine ESPA2-LD membranes for each indicated temperature (given in the inset along with the number of force measurements, $n$ ). Force curves in which snap-in events were not detected are tallied as the "NO" column. (d) Average snap-in force $\left(\bar{F}_{\text {snap }}\right)$ at each temperature calculated from (a-c) including the non-adhesive (i.e., purely repulsive approach) events as $\bar{F}_{\text {snap }}=0$ (* denotes statistical significance with $p<0.05$ ). (e) Average snap-in force $\left(\bar{F}_{\text {snap }}\right)$ at each temperature calculated from (a-c) excluding the non-adhesive events (* denotes statistical significance with $p<0.05$ ). Error bars denote one standard deviation. Data were collected in synthetic wastewater supplemented with $20 \mathrm{mg} \mathrm{L}^{-1}$ sodium alginate $\left(t_{\text {contact }}=5 \mathrm{~s} ; F_{\text {trigger }}=2 \mathrm{nN}\right.$; $\mathrm{pH} 7.4 ; I=14.7 \mathrm{mM})$. 


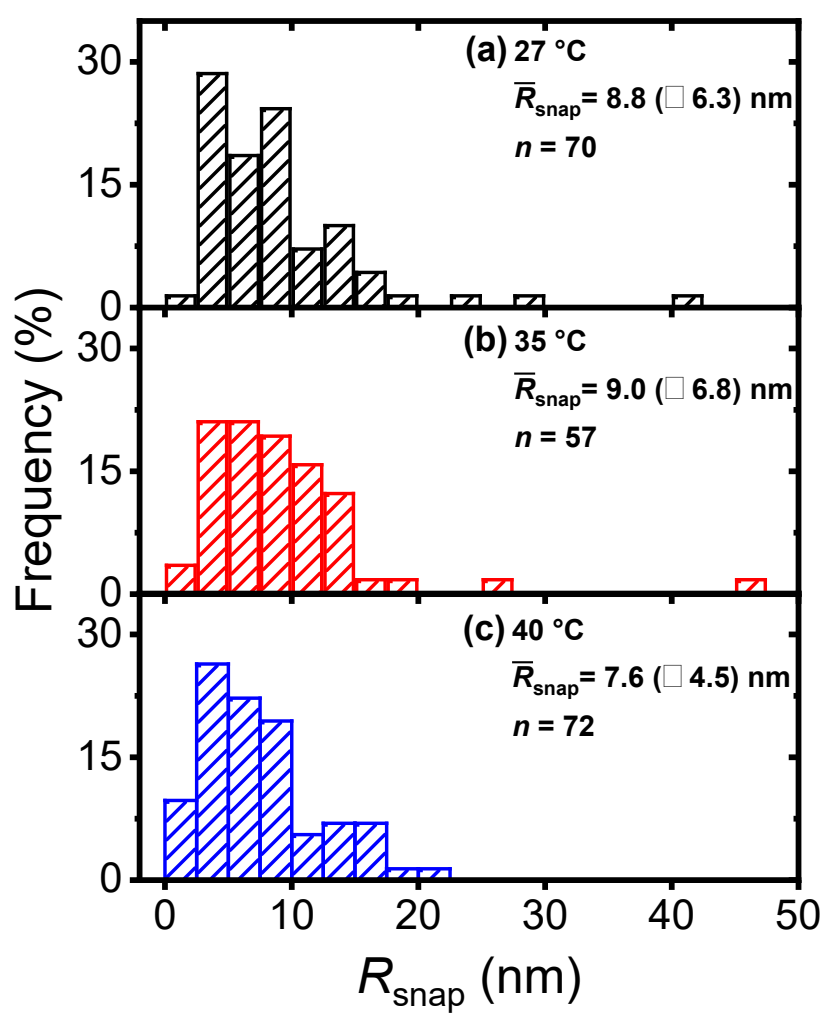

Figure S7: Distribution of snap-in distances $\left(R_{\text {snap }}\right)$ during adhesion of a CML colloidal probe to pristine ESPA2-LD membranes. Data were collected in synthetic wastewater supplemented with $20 \mathrm{mg} \mathrm{L}^{-1}$ sodium alginate at each indicated temperature (given in the inset along with the number of measurements $(n)$ and average snap-in distance $\bar{R}_{\text {snap }}( \pm$ standard deviation) $)$. Other experimental details: $t_{\text {contact }}=5 \mathrm{~s} ; F_{\text {trigger }}=2$ $\mathrm{nN} ; \mathrm{pH} 7.4 ; I=14.7 \mathrm{mM}$. Average snap-in distances are similar at all temperatures $(p>0.05$ for all pairwise comparisons). 


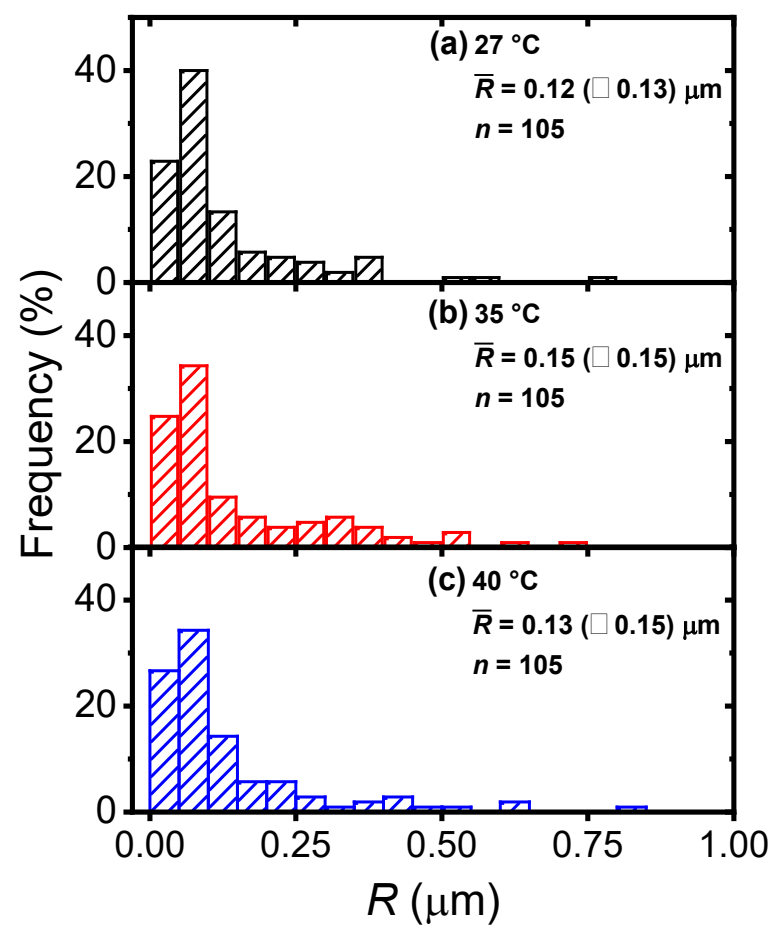

Figure S8: Distribution of rupture separations $(R)$ during adhesion of a CML colloidal probe to pristine ESPA2-LD membranes. Data were collected in synthetic wastewater supplemented with $20 \mathrm{mg} \mathrm{L}^{-1}$ sodium alginate at each indicated temperature (given in the inset along with the number of measurements $(n)$ and average rupture separation $\bar{R}$ ( \pm standard deviation)). Other experimental details: $t_{\text {contact }}=5 \mathrm{~s} ; F_{\text {trigger }}=2 \mathrm{nN}$; $\mathrm{pH} 7.4 ; I=14.7 \mathrm{mM}$. Average rupture separations are similar at all temperatures $(p>0.05$ for all pairwise comparisons). 


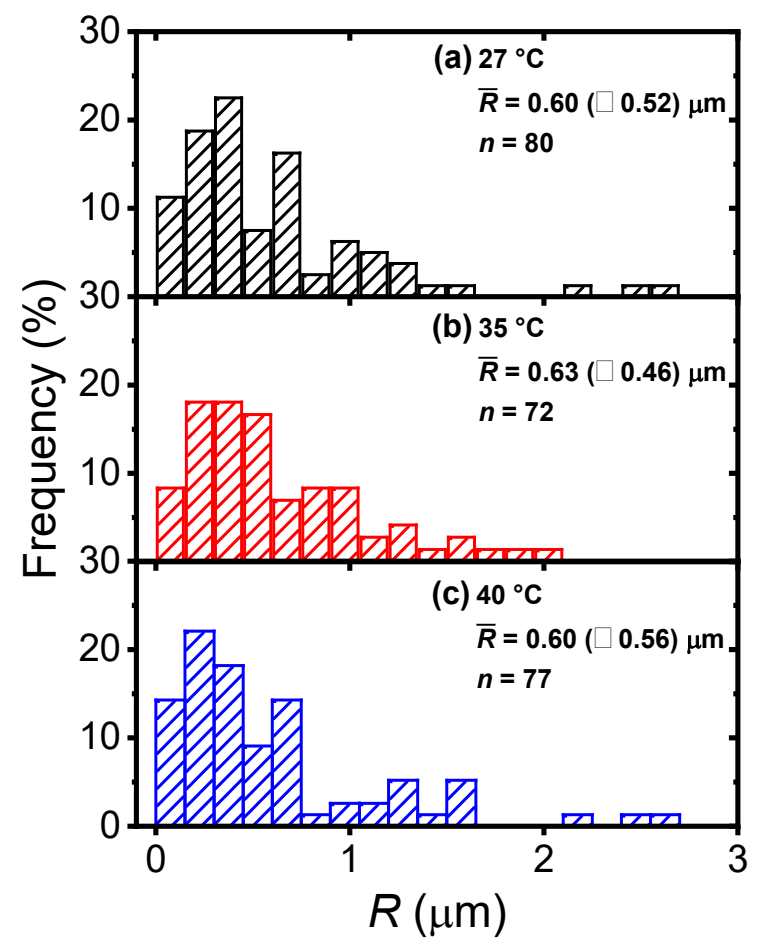

Figure S9: Distribution of rupture separations $(R)$ during adhesion of a CML colloidal probe to alginatefouled ESPA2-LD membranes. Data were collected in synthetic wastewater supplemented with $20 \mathrm{mg} \mathrm{L}^{-1}$ sodium alginate at each indicated temperature (given in the inset along with the number of measurements (n) and average rupture separation $\bar{R}$ ( \pm standard deviation)). Other experimental details: $t_{\text {contact }}=5 \mathrm{~s} ; F_{\text {trigger }}$ $=2 \mathrm{nN} ; \mathrm{pH} 7.4 ; I=14.7 \mathrm{mM}$. Average rupture separations are similar at all temperatures $(p>0.05$ for all pairwise comparisons). 


\section{References}

(1) Fujioka, T.; Khan, S. J.; McDonald, J. A.; Henderson, R. K.; Poussade, Y.; Drewes, J. E.; Nghiem, L. D. Effects of Membrane Fouling on N-Nitrosamine Rejection by Nanofiltration and Reverse Osmosis Membranes. J. Memb. Sci. 2013, 427, 311-319. https://doi.org/10.1016/j.memsci.2012.09.055.

(2) Fujioka, T.; Khan, S. J.; McDonald, J. A.; Roux, A.; Poussade, Y.; Drewes, J. E.; Nghiem, L. D. N-Nitrosamine Rejection by Reverse Osmosis: Effects of Membrane Exposure to Chemical Cleaning Reagents. Desalination 2014, 343, 60-66. https://doi.org/10.1016/j.desal.2013.10.032.

(3) Tiraferri, A.; Kang, Y.; Giannelis, E. P.; Elimelech, M. Superhydrophilic Thin-Film Composite Forward Osmosis Membranes for Organic Fouling Control: Fouling Behavior and Antifouling Mechanisms. Environ. Sci. Technol. 2012, 46 (20), 11135-11144. https://doi.org/10.1021/es3028617.

(4) Herzberg, M.; Elimelech, M. Biofouling of Reverse Osmosis Membranes: Role of Biofilm-Enhanced Osmotic Pressure. J. Memb. Sci. 2007, 295 (1-2), 11-20. https://doi.org/10.1016/j.memsci.2007.02.024.

(5) Standard Methods for the Examination of Water and Wastewater, 22nd ed.; Rice, E. W., Baird, R. B., Eaton, A. D., Clesceri, L. S., Eds.; American Public Health Association, American Water Works Association, Water Environment Federation, 2012.

(6) Xue, J.; BinAhmed, S.; Wang, Z.; Karp, N. G.; Stottrup, B. L.; Romero-Vargas Castrillón, S. Bacterial Adhesion to Graphene Oxide (GO)-Functionalized Interfaces Is Determined by Hydrophobicity and GO Sheet Spatial Orientation. Environ. Sci. Technol. Lett. 2018, 5 (1), 14-19. https://doi.org/10.1021/acs.estlett.7b00509.

(7) Binahmed, S.; Hasane, A.; Wang, Z.; Mansurov, A.; Romero-Vargas Castrillón, S. Bacterial Adhesion to Ultrafiltration Membranes: Role of Hydrophilicity, Natural Organic Matter, and Cell-Surface Macromolecules. Environ. Sci. Technol. 2018, 52 (1), 162-172. https://doi.org/10.1021/acs.est.7b03682.

(8) Wuolo-Journey, K.; Binahmed, S.; Linna, E.; Romero-Vargas Castrillón, S. Do Graphene Oxide Nanostructured Coatings Mitigate Bacterial Adhesion? Environ. Sci. Nano 2019, 6 (9), 2863-2875. https://doi.org/10.1039/c9en00499h.

(9) Goren, S. L. The Hydrodynamic Force Resisting the Approach of a Sphere to a Plane Permeable Wall. Colloid Interface Sci. 1979, 69 (1), 78-85.

(10) Kang, S.; Subramani, A.; Hoek, E.; Deshusses, M.; Matsumoto, M. Direct Observation of Biofouling in Cross-Flow Microfiltration: Mechanisms of Deposition and Release. $J$. Memb. Sci. 2004, 244 (1-2), 151-165. https://doi.org/10.1016/j.memsci.2004.07.011.

(11) Benjamin, M. M.; Lawler, D. F. Membrane Processes. In Water Quality Engineering Physical/Chemical Treatment Processes; John Wiley \& Sons, Inc.: Hoboken, NJ, 2013; pp 731-845.

(12) Sagle, A. C.; Van Wagner, E. M.; Ju, H.; McCloskey, B. D.; Freeman, B. D.; Sharma, M. M. PEG-Coated Reverse Osmosis Membranes: Desalination Properties and Fouling Resistance. J. Memb. Sci. 2009. https://doi.org/10.1016/j.memsci.2009.05.013.

(13) Olivas, G. I.; Barbosa-Cánovas, G. V. Alginate-Calcium Films: Water Vapor Permeability and Mechanical Properties as Affected by Plasticizer and Relative Humidity. LWT - Food Sci. Technol. 2008, 41 (2), 359-366. https://doi.org/10.1016/j.lwt.2007.02.015.

(14) Xie, M.; Lee, J.; Nghiem, L. D.; Elimelech, M. Role of Pressure in Organic Fouling in Forward Osmosis and Reverse Osmosis. J. Memb. Sci. 2015, 493, 748-754. 
https://doi.org/10.1016/j.memsci.2015.07.033.

(15) Kube, M.; Mohseni, A.; Fan, L.; Roddick, F. Impact of Alginate Selection for Wastewater Treatment by Immobilised Chlorella Vulgaris. Chem. Eng. J. 2019, 358, 1601-1609. https://doi.org/10.1016/j.cej.2018.10.065. 